\title{
LETTERS
}

\section{Look for an underlying cause of headache}

This letter is in response to a recent CMAJ article on medication-overuse headache. ${ }^{1}$ Patients do not start taking analgesics or triptans for no reason. In my experience, there is almost always an underlying chronic migraine condition. Once medication-overuse headache has been eliminated, you still need to find and treat the cause(s) of the underlying headache for the patient's condition to improve.

\section{Michael Zitney MD}

Director, Headache and Pain Relief Centre, Toronto, Ont.

n Cite as: CMAJ 2018 July 30;190:E915. doi: $10.1503 / \mathrm{cmaj} .69424$

\section{Reference}

1. Micieli A, Robblee J. Medication-overuse headache. CMAJ 2018;190:E296.

Competing interests: None declared. 